\title{
Genital Warts, Etiology, Signs, Treatment and Prevention
}

\author{
Arsalan Khan* \\ Livestock Research \& Development Station, Paharpur, Dera Ismail Khan, Pakistan \\ *Corresponding author: Arsalan Khan, Livestock Research \& Development Station, Paharpur, Dera Ismail Khan, Pakistan. \\ To Cite This Article: Arsalan Khan. Genital Warts, Etiology, Signs, Treatment and Prevention. Am J Biomed Sci \& Res. 2019 - 5(4). AJBSR. \\ MS.ID.000934. DOI: 10.34297/AJBSR.2019.05.000934.
}

Received: 眥 September 23, 2019; Published: 眥 September 30, 2019

\begin{abstract}
Genital warts, scientifically known as Condylomata acuminate, are the consequences of Human Papilloma Virus (HPV), probably one of the most occurring sexually transmitted infections. Human Papilloma Virus is non enveloped dsDNA virus and its predilection site are epithelium of genital organs. It belongs to the viral family Papoviridae, which replicates in the basal layer of genital epithelium. The genital mucosa may be infected anywhere including, penis, scrotum, vulva, vagina, cervix, anus, pubic and perianal area. Four subtypes of HPV 16, 18, 31, and 33, are known to cause cervical cancers, while HPV 6 and 11 cause 90\% cases of genital warts. Genital warts may commonly appear as lesions on penis, scrotum, vulva, vagina, cervix, anus, pubic and perianal area. The genital warts may be treated using $0.5 \%$ solution of Podophyllin, $25 \%$ solution of Podophyllotoxin, Imiquimoid 5\% cream, Trichloroacetic acid 60-90\% and Podophyllin resin 15\%. For the purpose of prevention of the disease vaccines are also available which are parentally administered.
\end{abstract}

Keywords: Podophyllin; Podophyllotoxin; Imiquimoid; Trichloroacetic acid

\section{Introduction}

Genital warts, scientifically known as condylomata acuminate, are the consequences of Human Papilloma Virus (HPV), probably one of the most occurring sexually transmitted infections. It is significantly public health problem because, it prone females at risk of cervical cancer as well as anal malignancy [1,2]. Warts are visible on external genitalia in the form of skin tags and lesions. Genital warts typically appear as flesh colored lesions on external genitalia and appear as small bumps on penis, scrotum, vulva, vagina, anus, pubic and perianal area, these may be flat or verrucous on the keratinized skin. Internal warts may also be produced in the vagina, cervix, urethra and even mouth [3].

\section{Etiology}

Human Papilloma Virus is non enveloped dsDNA virus and its predilection site are epithelium of genital organs. It belongs to the viral family Papoviridae, which replicates in the basal layer of genital epithelium. The genital mucosa may be infected anywhere including, penis, scrotum, vulva, vagina, cervix, anus, pubic and perianal area [4]Uptill now 120 subtypes of HPV are discovered out of which 16,18, 31, and 33 are high risk subtypes are confirmed for 4 cervical cancers while HPV 6 and 11 are rarely known to cause cervical cancers but are responsible for $90 \%$ cases of genital warts [5]. The viral genome comprises of six Early open reading frame genes i.e. E1, E2, E4, E5, E6 and E7 which are coded for regulatory function of the HPV while, two Late reading frame genes known as L1 and L2 are responsible for encoding viral capsid proteins [6].

\section{Signs and Symptoms}

The incubation period of the HPV ranges from 3 weeks to 8 months before it is clinically manifested. Most often the clinical manifestation and signs appear in 2 to 3 months of initial contact [7] The genital mucosa may be infected anywhere by HPV including the epidermis layer of penis, scrotum, vulva, vagina, cervix, anus, pubic and perianal area. These typically appear as flesh colored lesions and small bumps on the external genitalia, commonly referred as skin tags.

\section{Treatment and Prevention}

The primary goal of therapy is the removal of lesions or genital warts. Treatment may be through chemical agents or ablative. The warts are most successfully treated using $0.5 \%$ solution of Podophyllin or $25 \%$ solution of Podophyllotoxin. Moreover, Imiquimoid 5\% cream, Trichloroacetic acid 60-90\% and Podophyllin resin 15\% [8]. Commonly available vaccines for the prevention of genital warts are HPV2 Cervarix $®$ (GlaxoSmithKline) and HPV4 Gardasil ${ }^{\circledR}$ (Merk and Co.) 


\section{Reference}

1. Valerie RY, Rita V Patel, G. Goldenberg (2018) Genital Warts A Comprehensive Review. J Clin Aesthet Dermatol 5(6): 25-36.

2. Walboomers JM, MV Jacobs, MM Manos, Bosch FX, Kummer JA, et al. (1999) Human papillomavirus is a necessary cause of invasive cervical cancer worldwide. J Pathol 189(1): 12-9.

3. Batteiger BE (2000) External genital warts. Best Pract Med 9(10): 312314.

4. Ghayas S, F Anjum, T Husain, L Bashir, S Naz, et al. (2018) Human papillomavirus and its vaccine: awareness and attitudes of young female
Pakistani students. Human papillomavirus and its vaccine: awareness and attitudes of young female Pakistani students 10(4): 200-205.

5. Scheinfeld N, DS Lehman (2006) An evidence-based review of medical and surgical treatments of genital warts. Dermatol Online J 12(3): 5.

6. Winer RL (2003) Genital human papillomavirus infection: incidence and risk factors in a cohort of female university students. Am J Epidemiol 157(3): 218-226.

7. Wiley DJ (2003) Genital warts. Clin Evid 9: 1741-1753.

8. Charles M Kodner, S Nasraty (2004) Management of genital warts. American Family Physician 70(12): 2335-2342. 